\title{
SCIENCE CHINA \\ Technological Sciences
}

\section{- Special Topic on High Performance Steels •}

July 2012 Vol.55 No.7: 1773

doi: 10.1007/s11431-012-4908-4

\section{Editorial}

Steel has been a milestone for the human civilization, and has been still playing a very important role in our society today. It is hard for ones to image what the world would be if there were no steels at all.

Steel is an old lexicology name for a group of materials over thousands of years, it changes day by day. The steels we are familiar with today are totally different from the steels our ancestor used hundreds years ago, even totally different from the steels decades ago. Typical examples are the X80 steel for pipeline and TRIP steel for automobile. It is hard for one to image what the steel will look like in the future. Thanks to the sound understanding in steel science, this consistent change could take place steadily. Steel may now be considered to be one of the new materials due to its characteristics of high performance, lower cost, abundant production, ease of use and recycling.

The demands to improve steel properties have never stopped, because, among others, high-rise and long-span buildings demand high strength steel with lower yield ratio; lightweight automobiles also require high strength steel with improved ductility; high efficiency fossil power stations need steels with high creep strength at even higher temperatures. There are increasing requirements from the market for steel to be upgraded to be of even high performance.

The production and application of steel have a strong impact on the society. It is really amazing that almost half of the crude steels in the world (46\% in the year of 2011) is produced in China. Although it gives the support for the development of our society, this situation has inevitably brought about some drawbacks, such as shortage in the resources, heavy burden to the environment and lower benefits from the market. One of the ways to solve those problems is to improve the performance of steel, which would reduce the consumption of steel and promote the efficiency of steel applications.

Nowadays, it is not very difficult to raise the strength of the steel over $1000 \mathrm{MPa}$ or even to $2000 \mathrm{MPa}$. The key point is to obtain the optimum balance between strength and other properties, such as toughness, ductility, weldability, formability, cost, etc. It generally contradicts the common knowledge to improve the properties stated above simulta- neously, but we should do it for the sake of requirements from end users and sustainable development.

It is time for us to keep up basic studies of steels from the fundamental understanding and find the new way to improve the performances of the steel products. In 2009, we proposed a novel idea to control the microstructure of multi-phase, meta-stable, and multi-scale (so-called $\mathrm{M}^{3}$ microstructure) for the improvement of performances. We have been focusing on three prototype steels: the high strength low alloy steel for infrastructure to improve toughness and/or ductility; high strength automobile sheet steel to improve ductility and formability; heat resistant martensitic steel for USC boilers working at $650^{\circ} \mathrm{C}$ to improve creep strength. In order to achieve the target, it is also necessary to guarantee high cleanliness in melting and high uniformity in solidification concerning with the steel processing technology.

In 2010, the Ministry of Science and Technology of China launched a new phase of "973 Program" entitled "High Performance Steels through Novel Microstructure Control". Over eighty talent researchers from eight research institutes and universities in China have been involved in the Program. Thanks to their great contributions in the understanding of the phenomena and theoretical interpretation, a glow of the dawn could be seen over the sky of steel technology for high performance steels. There are some important creations in the new benchmark technology to improve the performances of the steel products.

As the chief scientist of the Program, I would like to express my sincere thanks for the publishing promotion and hard work of the editor, Dr. WANG Jing of the Journal. I hope this special issue on the high performance steel could give a quick look into the progresses of the Program and could promote the interests on the steel study and steel product development. I and my colleagues who are involved in the Program do believe the steel in the near future will change differently from what we have today.

DONG Han

Central Iron \& Steel Research Institute

May 4, 2012 